\section{La inclusión cultural en las normativas migratorias de la República Argentina en el contexto sudamericano (1983-2018)*}

\section{Cultural inclusion in the Argentine migratory regulations in the South American context (1983-2018)}

\author{
Diego Sebastián Crescentino ${ }^{* *}$ \\ UNIVERSIDAD AUTÓNOMA DE MADRID, ESPAÑA \\ $\triangle$ diego.crescentino@uam.es \\ https://orcid.org/0000-0002-0780-199x
}

\author{
Anuario Latinoamericano \\ Ciencias Políticas \\ y Relaciones Internacionales \\ vol. 6, 2018 \\ pp. $103-120$
}

DOI: $10.17951 / \mathrm{al} .2018 .6 .103-120$

\title{
RESUMEN:
}

Este artículo tiene por objetivo recuperar el debate en torno a la inclusión cultural de los migrantes en el ordenamiento legal argentino (1983-2018), prestando atención a las iniciativas regionales de integración en el contexto sudamericano. Para ello, se realiza un esbozo teórico en torno al concepto de política cultural. Posteriormente, se analizan las normativas migratorias argentinas desde 1983, la ley migratoria vigente y el ordenamiento legal surgido desde su promulgación, exponiendo aquellos puntos consagrados a la inclusión cultural. Paralelamente, se examina la influencia recíproca existente entre el ordenamiento migratorio argentino y los acuerdos alcanzados por organismos supranacionales. A modo de cierre, se expone la incipiente institucionalización de iniciativas de integración cultural regional.

PALABRAS CLAVE: Argentina, leyes migratorias, inclusión cultural, Sudamérica, instituciones regionales de integración cultural.

\section{ABSTRACT:}

This paper seeks to recover the debate on the cultural inclusion of migrants in the Argentine legal system (1983-2018), paying attention to regional integration

\footnotetext{
* Este texto forma parte de una investigación financiada por el programa de contratos predoctorales FPI-UAM del Departamento de Historia Contemporánea de la Universidad Autónoma de Madrid.

** Personal Investigador en Formación en el Departamento de Historia Contemporánea de la Universidad Autónoma de Madrid. Investigador de la Universidad Nacional de Cuyo. Máster en Relaciones Internacionales y Estudios Africanos de la Universidad Autónoma de Madrid. Licenciatura en Ciencia Política y Administración Pública de la Universidad Nacional de Cuyo.
} 
initiatives in the South American context. For this, I expose a theoretical sketch around the concept of cultural policy. After that, I analyse the Argentine immigration regulations since 1983, the current immigration law and the legal order that emerged from its promulgation, exposing those points devoted to cultural inclusion. At the same time, I examine the reciprocal influence existing between the Argentine migratory order and the agreements reached by supranational organizations. By way of closing, I explain the incipient institutionalization of regional cultural integration initiatives.

KEYWORDS: Argentina, migratory laws, cultural inclusion, South America, regional institutions for cultural integration.

\section{Introducción}

El problema de fondo relativo a los derechos humanos no es hoy tanto el de justificarlos como el de protegerlos. Es un problema no filosófico sino jurídico y, en sentido más amplio, político. (...) [S]e trata (...) de saber (...) cuál es el modo más seguro para garantizarlos, para impedir que, a pesar de las declaraciones solemnes, sean continuamente violados (Bobbio 1991: 61).

A lo largo de toda la década de 1990 y hasta el año 2003, el Congreso argentino albergó el debate de la redacción de una nueva ley de migraciones que reconociera la migración como un derecho humano. Este artículo tiene por objetivo recuperar el debate en torno a su promulgación desde la perspectiva de la integración intercultural, prestando atención a la interacción de dicha normativa con las iniciativas de los principales organismos supranacionales de la región (MERCOSUR y UNASUR). A catorce años de la promulgación de esta ley e inmersos en los albores de un posible debate por una reforma hacia caminos más restrictivos, este diálogo resulta esencial a la hora de formular un diagnóstico que persiga la actualización de las normativas migratorias en pos de lograr una verdadera (y postergada) inclusión cultural.

Para ello realizaré en primer lugar un esbozo teórico en torno al concepto de política cultural. Ello será proseguido por un análisis somero de las normativas migratorias argentinas desde la restauración de la democracia. Posteriormente, examinaré la ley migratoria vigente y el ordenamiento normativo surgido a partir de su promulgación, exponiendo con mayor precisión aquellos consagrados a la inclusión cultural de los inmigrantes. A la vez, observaré la influencia recíproca existente entre el ordenamiento migratorio argentino y los acuerdos alcanzados por organismos supranacionales en pos del establecimiento de puntos en común en las normativas migratorias regionales en el ámbito de la inclusión intercultural. Con ello pasaré, a modo de cierre, a una breve exposición de la incipiente institucionalización de iniciativas de integración cultural regional a nivel supranacional. 


\section{Un punto de partida: política cultural}

Las políticas culturales son políticas públicas realizadas por el Estado, organizaciones civiles y grupos comunitarios organizados “a fin de orientar el desarrollo simbólico, satisfacer las necesidades culturales de la población y obtener consenso para un tipo de orden o de transformación social" (García Canclini 2001: 63). Desde un punto de vista histórico, el germen de las políticas culturales en Argentina puede ser encontrado en el proceso de conformación del Estado Moderno, a través del cual la necesidad de relacionar Estado y Nación tuvo como eje fundamental la construcción de una cultura nacional común como núcleo integrador de la sociedad gobernada. En este sentido, las políticas culturales estatales sirvieron en gran parte a los intereses ideológicos de la élite dominante, con el fin de construir un imaginario colectivo que homogeneizara a la población y permitiese con ello establecer un orden social apoyado en los principios liberales.

Como consecuencia, el Estado se vio comprometido con la regulación, sobre todo, de las artes cultas eurocéntricas (a fin de reproducir los valores de las élites); el folklore y las artes populares; y el patrimonio inmueble (Yúdice 2002: 215). Esta estructura se mantuvo relativamente estable a lo largo del siglo xx. A partir de los años 80, la globalización y el advenimiento del neoliberalismo llevaron a un proceso de atomización de las funciones del Estado y su subordinación ante el mercado o actores supraestatales. Ello tuvo como resultado la generación de proyectos de descentralización que, en el ámbito de la producción de políticas culturales, originaron procesos contradictorios de concentración de las industrias culturales en manos privadas en algunos casos y democratización de la producción cultural en otros. Esta doble transformación condujo a la necesidad de replantear los mecanismos de construcción y regulación de políticas culturales.

Ante una realidad en la cual las industrias culturales "atraviesan fronteras, nos agrupan y conectan en forma globalizada" (García Canclini 2001: 64), los diagnósticos que partían de la idea del Estado Moderno como actor único y determinante en la construcción de políticas culturales comenzaron a ser revisados. Por otra parte, la diversidad cultural multiplicó "en forma real y virtual las interacciones y las experiencias de alteridad, en virtud de los flujos poblacionales, mediáticos e informacionales" (Gavazzo 2004: 5). Ello se dio en un contexto en el cual la presión ejercida por las ideas del multiculturalismo desde las academias norteamericanas sirvió como base de la narrativa de la democracia liberal triunfante en el periodo post Guerra Fría. Este cúmulo de factores condujo en Argentina a nuevos debates centrados en el fomento de la admisión legal de la diversidad cultural como método de democratización de la cultura en un entorno global, haciendo partícipes en ello tanto a la sociedad y al tercer sector como al sector privado (Yúdice 2002: 215).

No obstante, bajo esta concepción de tolerancia se generaron, a su vez, nuevos mecanismos de clasificación de las diferentes expresiones culturales
La inclusión cultural en las normativas migratorias de la República Argentina en el contexto sudamericano (1983-2018)

Diego Sebastián Crescentino 
Dossier América Latina: fronteras y zonas fronterizas

según una "moral universal" que condujo al mantenimiento del estatus quo. De este modo, desde una posición global vacía otorgada por una condición universal privilegiada (Žižek 1998: 172), se proponía la tolerancia a la diversidad cultural, invisibilizando desde lo neutral un fomento de políticas culturales que homogeneizaban las diferencias interculturales y exigían el "respeto" a las identidades nacionales establecidas. Este modelo de comprensión cultural suponía la igualdad formal entre los grupos sociales y étnicos, y se apoyaba en una visión de reciprocidad y consenso entre ellos, a la vez que promovía un discurso de aceptación, tolerancia y respeto de las diferencias culturales. Mientras tanto, a nivel práctico, confiaba en una "mejora en la comunicación" de los diferentes grupos étnicos y en el "cambio de actitudes" para revertir los prejuicios. Ello llevó como consecuencia a hacer hincapié en programas de sensibilización y formación en relaciones humanas (Domenech y Magliano 2008: 435).

Por esto mismo es que, de la mano del leitmotiv de la integración y la tolerancia intercultural, "las políticas gubernamentales y empresariales [recurrieron] cada vez más a la cultura como estrategia de promoción, venta y consumo" (Gavazzo 2004: 5). Como consecuencia, la búsqueda por lograr cada vez mayores proporciones de poder en la propiedad de las industrias culturales formando grandes monopolios- se transformó en una disputa constante entre el Estado, las empresas y todo tipo de agentes sociales que pretendían obtener algún rédito de ello.

\section{El ordenamiento legal argentino en el período 1983-2003}

Como señala Rubén Giustiniani, propulsor de la ley de migraciones vigente, a lo largo de la historia argentina es posible contemplar una constante particular si analizamos el rol de los gobiernos en la cuestión migratoria: hasta 2003, las normas de fondo habían sido formuladas por gobiernos conservadores y/o militares. Por medio de un espíritu netamente represivo y desde una perspectiva de control, estas regulaciones buscaron plasmar prejuicios racistas, xenofóbicos y discriminatorios ${ }^{1}$. De este modo procuraron, a su vez, acentuar el espíritu nacional como un factor de diferenciación a nivel regional, destacando la ascendencia europea de la identidad argentina e invisibilizando la presencia tanto de pueblos originarios como de corrientes migratorias regionales. Estas normas de base no fueron debatidas ni rechazadas en períodos democráticos, sino que fueron mantenidas y profundizadas luego de que los gobiernos de facto abandonasen el poder (Giustiniani 2004: 34).

\footnotetext{
1 Por supuesto, también existió una promoción de políticas xenófobas, racistas, discriminatorias y con criterios utilitaristas por gobiernos democráticos, que luego también fueron mantenidas por las dictaduras.
} 
Tal fue el caso del Decreto-Ley 22.439 General de Migraciones y de fomento de la inmigración firmado por el presidente de facto Rafael Videla en 1981, normativa que se mantuvo vigente en el país por más de dos décadas tras el retorno de la democracia. Aún más, las múltiples reformas al Reglamento de la Ley General de Migraciones ${ }^{3}$ sólo contribuyeron a acentuar el carácter restrictivo de las políticas migratorias vigentes (Oteiza 2004: 92).

Los constantes vaivenes de una economía nacional y regional inestable, con crisis cíclicas causadas por presiones financieras producto del fuerte endeudamiento internacional, se sumaron al establecimiento de un modelo de Estado neoliberal en lo económico y neoconservador en lo social, cuyo achicamiento en sus funciones en el ámbito de los derechos sociales se tradujo en un fortalecimiento de su brazo represivo. Como consecuencia, durante las décadas de los 80 y los 90, las políticas migratorias circularon sobre dos caminos paralelos y contradictorios. Mientras la continuidad del Decreto-Ley de la dictadura mantenía las dificultades para la radicación legal de los inmigrantes; la elaboración de leyes, decretos, reglamentos y dictámenes se debatían en un vaivén entre el endurecimiento de las políticas restrictivas y el avance de normas ad hoc y convenios bilaterales para regularizar la situación de la población indocumentada (Mármora 2004: 60-61).

La segunda de estas posturas, sin embargo, continuó despertando grandes oposiciones toda vez que se intentó hablar de la necesidad de una nueva ley de migraciones. En este sentido, la arraigada narrativa en torno a una pretendida identidad europea que tan fieramente habían defendido las élites argentinas desde la primera ley de migraciones (1876), había echado profundas raíces en el imaginario social de la población. Durante la década de 1990, tanto políticos, funcionarios y medios de comunicación como una sociedad que, ante el empeoramiento de sus condiciones de vida, buscaba a quien culpar, centraron sus energías en la falsa, pero muy difundida noción de una explosión de la inmigración en Sudamérica. El fortalecimiento del mito de un flujo cada vez mayor de inmigrantes limítrofes que invadían las grandes ciudades y ponían en peligro las costumbres nacionales, sus puestos de trabajo y la seguridad de la población, se vio fortalecido por una política oficial de hipervisibilización de las diferencias que chocaba profundamente con el fomento de las ideas multiculturales de reconocimiento de derechos (Oteiza 2004: 95-102 y Grimson 2006: 69-71).

Tal fue el contexto que tuvo que afrontar el debate de una nueva normativa general de migraciones -la tercera de la historia argentina-, superando las resistencias de gran parte de la clase política y la sociedad desde el momento

2 Entre los años 1976 y 1983, la disolución del Congreso Nacional establecida por la dictadura cívico-militar llevó al gobierno de facto a dictar normativas de carácter legislativo sin autorización previa del Congreso. A estas figuras legales se les denominó Decretos-Leyes.

3 El reglamento aprobado por el Decreto $1434 / 1987$ y los reglamentos aprobados por los Decretos 1023/1994 y 1117/1998.
La inclusión cultural en las normativas migratorias de la República Argentina en el contexto sudamericano (1983-2018)

Diego Sebastián Crescentino 
Dossier América Latina: fronteras y zonas fronterizas mismo de la recuperación de la democracia en 1983. Así, la instauración del modelo económico importado a partir del Consenso de Washington dio curso a un conjunto de decretos y reglamentaciones que evidenciaron "la inexistencia de una política poblacional integrada a un proyecto de Nación, así como la manifestación de la primacía de conceptos retrógrados cargados de prejuicios" (Giustiniani 2004: 14). Con el gobierno de Carlos Saúl Menem se inició un paradójico proceso en el cual la búsqueda de mercados libres y desregulados enfrentó la necesidad de integración económica con la ausencia de una integración política, social o cultural y bajo la cual los procesos de hibridación superaron las obsoletas fronteras nacionales. En este complejo contexto sociocultural, la lógica transnacional pujó fuerte a fin de mantener la idea de una aldea global limitada a la liberación de flujos económicos y financieros.

Sin embargo, los debates iniciados a nivel político y académico de la mano del modelo de gestión multiculturalista postulado a nivel internacional también se dieron a nivel local, a través de un proceso de reforma del Estado argentino que abogó por la adopción de una perspectiva de gestión de la integración apoyada en la tolerancia y el respeto. Es así que, si bien el debate en torno a la ley de migraciones que finalmente se aprobaría no inició hasta 1997, la reforma de la constitución nacional del año 1994 marcó un punto de inflexión en el sistema legal argentino. La definición de la necesidad de reforma constitucional fue establecida a través de la Ley No 24.309/1993, declarando en su tercer artículo que se habilitaba a la Convención Constituyente a debatir, entre otros, la inclusión de nuevos derechos y garantías entre los derechos fundamentales de la República. En efecto, este nuevo panorama se vio marcado por el reconocimiento del carácter constitucional de múltiples tratados internacionales y el progreso del diálogo a nivel regional que condujo a la constitución del MERCOSUR. Estos fenómenos fueron pioneros a nivel regional en la búsqueda de respuestas conjuntas por medio de normativas y organizaciones supranacionales, que permitieran incorporar la integración regional a la agenda y los discursos políticos.

A pesar de ello, el carácter represivo del Estado recrudeció entre 1995 y 1999, mostrando la peor cara del Decreto-Ley Videla desde la recuperación de la democracia a través de un mayor empoderamiento de la Dirección Nacional de Migraciones. Tal fue el objetivo de los Decretos Reglamentarios No 1023/1994 y No 1.117/1998, que, a partir de un mayor control y concentración de poder de decisión en el Ministerio del Interior y una mayor delegación de funciones a la Dirección Nacional de Migraciones, complejizaron el trámite migratorio (Pacceca 1997: online). Paradójicamente, en 1995 apareció en escena un organismo descentralizado esencial en el reconocimiento de los graves problemas de discriminación existentes en la sociedad argentina: el Instituto Nacional contra la Discriminación, la Xenofobia y el Racismo (INADI) en el entorno del "Programa Contra la Discriminación".

En este vaivén de contradicciones, la creación de la Reunión de Ministros del Interior del MERCOSUR y Estados Asociados en el año 1996 abrió 
un espacio para el establecimiento de las bases de una política migratoria en bloque como parte del proceso de integración regional. Esta idea fue profundizada recién en el año 2002, con el Acuerdo de Residencia del Mercosur. Allí se planteó por primera vez a nivel oficial la necesidad de la libre circulación de personas en la región, haciendo de la nacionalidad un nuevo criterio de acceso a la residencia regular: toda persona nacida en un país del bloque debería tener la posibilidad de acceder a una residencia temporaria con permiso de trabajo por dos años en cualquier país miembro o asociado, e incluso transformarla en permanente mediante solicitud dentro de los 90 días anteriores a su vencimiento si se podía acreditar medios de vida lícitos e inexistencia de delitos penales. A partir de entonces, esta política fue paulatinamente introducida por los diferentes Estados suscriptores.

Con el triunfo del gobierno de la Alianza por el Trabajo, la Justicia y la Educación en el año 1999, el agotamiento del modelo económico neoliberal se volvió incuestionable. Ante una realidad social por demás conflictiva y el surgimiento de grupos de desocupados, el gobierno de coalición propuso constantes planes de ajuste para resolver los grandes problemas coyunturales a los cuales se enfrentó. En este contexto, el rechazo de la vigente ley de migraciones y la presión de organizaciones de la sociedad civil por una nueva ley llevó a que la cuestión migratoria volviera al centro del debate político.

Fue entonces en el año 1999 cuando el Diputado Rubén Giustiniani, presidente de la Comisión de Población y Desarrollo Humano de la Cámara, comenzó una labor de integración de los proyectos de ley presentados a lo largo de los años previos. Ello dio lugar a dos actividades integradoras a partir de las cuales nació el espíritu de la Ley: el Seminario sobre Política Demográfica de la Comisión de Población y la Audiencia Pública. En los mismos, la interrelación de organismos del Estado, legisladores, expertos, funcionarios, colectividades, representantes de organismos de derechos humanos e iglesias debatieron las necesidades a ser contempladas por una nueva Ley.

Paralelamente tuvieron lugar, por un lado, la Conferencia Ciudadana contra el Racismo, la Xenofobia, la Intolerancia y la Discriminación en Santiago de Chile (2000), ligada a la Conferencia Mundial contra el Racismo, la Discriminación Racial, la Xenofobia y las Formas Conexas de Intolerancia en Durban (2001); y por el otro, la Conferencia Suramericana sobre Migraciones en Lima, a partir del Encuentro Suramericano sobre Migraciones, Integración y Desarrollo a nivel subcontinental. En este último, los gobiernos de la región se comprometieron a priorizar el mantenimiento de consultas regulares interestatales, analizando los movimientos migratorios. Ello se cristalizó en el año 2000 en la I Conferencia Suramericana sobre Migraciones (CSM) en la ciudad de Buenos Aires, la cual continúa realizándose año tras año hasta la actualidad y a partir del año 2007 fue integrada al Foro Mundial sobre Migración y Desarrollo dependiente de Naciones Unidas. En el 2010, con la aprobación del Plan Sudamericano de Desarrollo Humano de las Migraciones, se dio origen al Observatorio Suramericano Sobre Migraciones (OSUMI), cuyo objetivo
La inclusión cultural en las normativas migratorias de la República Argentina en el contexto sudamericano (1983-2018)

Diego Sebastián Crescentino 
Dossier América Latina: fronteras y zonas fronterizas es el intercambio y divulgación de información sobre ámbito migratorio en definición de políticas acordes a los estándares internacionales de derechos humanos.

El trabajo en red de todos estos organismos fue esencial para la identificación de las necesidades a satisfacer en torno a la cuestión migratoria, lo cual llevó a que en el año 2000 se formalizara legalmente la Mesa de Organizaciones en Defensa de los Derechos de los Inmigrantes ${ }^{4}$. Los informes realizados por esta institución establecieron los principios sobre los cuales se asentaría la nueva normativa. Estas nuevas iniciativas de participación, sumadas a la coordinación con la nueva administración de la Dirección Nacional de Migraciones llevaron a un gran acuerdo que, tras dos oportunidades, concluyó en la discusión de la Ley en la última sesión del Congreso del año 2003 y su sanción.

\section{La ley argentina de migraciones: del asimilacionismo al multiculturalismo}

Lo fundamental del establecimiento de una política migratoria -y demográfica en general- es que a través de esta los individuos son clasificados y categorizados, de modo que les son reconocidos diferentes derechos, estatus y roles. Así pues, estas políticas influyen y modelan constantemente la vida de las personas. Siguiendo estas ideas, una ley de migraciones es el mensaje que se da tanto a los destinatarios de esta -extranjeros- como a la población en general, ya que la misma expresa el lugar que se asigna a los inmigrantes en la sociedad (Modolo, Novick y Mera 2010: 2). La doctrina de seguridad internacional inaugurada tras los atentados del 11 de septiembre de 2001 en Estados Unidos, las constantes intervenciones de la OTAN en el Magreb y Oriente Próximo, el fracaso de la "guerra contra el terror" y la consiguiente incubación de la crisis de refugiados internacional ha conducido como consecuencia a la generación masiva de políticas y discursos que buscasen reducir abruptamente la movilidad internacional.

En Argentina, la presencia de un Estado históricamente represivo ante el ingreso de inmigrantes contrarios a la "voluntad y la costumbre nacional" y ausente en su integración sociocultural, llevó a una cesión real de la responsabilidad de ampararlos a organismos de la sociedad civil. Ello dio como resultado que fueran estas organizaciones las que, ante la omisión del Estado, comenzaran a gozar de cierta injerencia en las decisiones gubernamentales (Mardones 2005: 62). Y fue por ello gracias a estas que, tras años de trabajo,

\footnotetext{
4 Más allá de que la misma ya había estado trabajando informalmente desde el año 1996. Para un análisis más detallado sobre el tema véase Correa V. (2006), El papel de la sociedad civil en los derechos humanos de los migrantes, CELADE, Santiago de Chile.

5 Como versaba la segunda generación de leyes migratorias argentinas, como las leyes 4144 de Residencia de Extranjeros de 1902, o 7209 de Defensa Social de 1910.
} 
el 21 de enero de 2004 la Ley de Migraciones No 25.871 entró finalmente en vigor, transformándose en la primera ley de fondo que versaba sobre la cuestión migratoria dictada por autoridad constitucional desde 1876. La experiencia de un extenso trabajo en red de organizaciones de la sociedad civil convirtió el proyecto migratorio argentino en un ejemplo a nivel regional, aplicado en las experiencias políticas de otros países sudamericanos, como el caso de Ecuador (2004), Uruguay (2008), Bolivia y Perú (2013).

En oposición a la mencionada doctrina de seguridad internacional, el fundamento teórico básico que dio origen a la nueva Ley de Migraciones fue la comprensión de la migración como un derecho humano en línea con las convenciones internacionales de Naciones Unidas y la Organización Internacional del Trabajo, y consolidada como política regional del MERCOSUR. Sus iniciadores se propusieron para ello encaminarse hacia la integración y no la exclusión, el multilateralismo de la regionalización y no el unilateralismo, en la tolerancia y no en la xenofobia (Giustiniani 2004: 14-15).

Surgida de la necesidad de poner fin a la vigencia del Decreto- "Ley Videla" y de definir las bases fundamentales para una política migratoria y poblacional de cara al siglo xxi y a las nuevas realidades del contexto regional e internacional, la nueva normativa buscó restablecer los derechos que una persona pierde en el acto de cruzar la frontera hacia otro territorio y asegurar el cumplimiento de sus obligaciones como habitantes de otro territorio. Para ello, reconoció legalmente los derechos de los migrantes comprendidos por los artículos 20 y 25 de la Constitución Nacional argentina; además de aquellos derechos generales destinados a todos los habitantes del país, como el Preámbulo y los artículos 14, 14 bis, 15, 16, 18, 19, 41, 42 y 43. A ellos se sumaron los acogidos por los tratados internacionales reconocidos por la constitución de 1994. De esta manera, se pasó en teoría de una ley, cuyo fundamento era establecer como rol del Estado argentino el control y la prohibición a través de una rigurosa selección migratoria, a una ley en la cual el Estado pasaba a ser el garante del derecho a migrar.

El modelo de sociedad subyacente en la nueva ley no fue en principio un crudo reflejo de la sociedad disciplinaria, discriminadora según el origen de los migrantes, sino que estableció una sociedad multicultural, "integrada en la región e inclusiva, que respeta los derechos de los extranjeros y valora su aporte cultural" (Novick 2004: 84-85). Se pasó de una retórica de la exclusión, que observaba a los inmigrantes como amenaza, a una retórica de la inclusión, donde la inmigración pasó a ser considerada como contribución (Domenech 2010: 40).

En el ámbito de la integración sociocultural —una de las grandes deudas históricas de las leyes migratorias argentinas-, el artículo 7 de la ley garantizó la educación de todos los inmigrantes que así lo deseasen, sin que en ningún caso la irregularidad migratoria fuese causa de impedimento para su acceso a las instituciones educativas de cualquier nivel. El artículo 14, por su parte, contempló la integración de los extranjeros en la comunidad de residencia
La inclusión cultural en las normativas migratorias de la República Argentina en el contexto sudamericano (1983-2018)

Diego Sebastián Crescentino 
Dossier América Latina: fronteras y zonas fronterizas

garantizada por el Estado como un objetivo primordial ${ }^{6}$. Estos reconocimientos estuvieron limitados empero por el artículo 125 a la "obligación a respetar la identidad cultural de los argentinos”. Ello implicó que, como máximo, las demandas de las minorías culturales fueran reconocidas siempre y cuando no representasen una amenaza a la "cultura nacional". Se ofreció a los inmigrantes integrarse a la cultura nacional dominante a costa de su marginación, conservando aquellas particularidades identitarias que no resultasen amenazadoras para dicha cultura (Domenech 2005: 3).

Por otra parte, esta normativa dejó relegada a la reglamentación y a las normativas complementarias la forma en que ello iba a ser llevado a cabo, limitándose a señalar la necesidad de formular políticas públicas de integración desde una perspectiva intercultural. Tanto en el ámbito de la integración como en la gestión de la interculturalidad, el reconocimiento de derechos propiciado por la ley no fue acompañado por un acompañamiento global de políticas de Estado ni desde el Ministerio de Educación, ni desde la Secretaría (desde 2014 Ministerio) de Cultura. La presencia de estructuras previas y la falta de coordinación entre ambas configuraciones institucionales en la temática de la gestión intercultural fue el principal límite a la ley en este aspecto.

Ello llevó a que ya en el informe del Centro de Estudios Legales y Sociales (CELS) del año 2011 se indicara que "hasta el momento, pocas o nulas han sido las medidas y políticas concretas que se adoptaron para garantizar esa integración, particularmente desde una perspectiva intercultural" (Ceriani Cernadas y Morales 2011: 24). En este sentido, ninguna de estas políticas tuvo éxito al no verse acompañadas en el proceso de integración regional.

Ahora bien, la necesaria reglamentación de la ley por medio de la cual debían instrumentalizarse estos artículos, se formalizó únicamente en el año 2010. La demora se debió en parte a las dificultades a enfrentar en el seno de la institucionalidad de la Dirección Nacional de Migraciones, regida por una lógica represiva predominante vigente a lo largo de toda su historia. Desde el momento de la promulgación de la ley y hasta el año 2008, tanto la Dirección Nacional de Migraciones como la Mesa de Organizaciones para la Defensa de los Derechos Humanos de los Migrantes elaboraron múltiples propuestas de reglamentación de la ley en un tire y afloje constante de posiciones difícilmente compatibles. Sin embargo, todas las propuestas de la Dirección Nacional de Migraciones fueron impugnadas u observadas por la Mesa por su carácter represivo.

Fue sólo en el mes de junio del año 2008 cuando se dio un hecho fundacional para reglamentación final de la ley. A través de la Disposición de la Dirección Nacional de Migraciones No 37130/2008 y a instancias del Ministerio del Interior, se creó una Comisión Asesora para la Reglamentación de la

\footnotetext{
6 A través de su integración idiomática, la instrucción sobre sus derechos y obligaciones, la valoración de sus expresiones culturales y la organización de cursos de formación a funcionarios públicos y privados inspirados en la convivencia de una sociedad multicultural.
} 
Ley, invitando a participar en ella a algunas organizaciones integrantes de la Mesa -Centro de Estudios Legales y Sociales (CELS) y Asamblea Permanente por los Derechos Humanos (APDH) - , organizaciones internacionales Organización Internacional de Migraciones (OIM) - , organismos de Naciones Unidas - Alto Comisionado de las Naciones Unidas para los Refugiados (ACNUR) - y algunas instituciones religiosas - Fundación Comisión Católica Argentina de Migraciones (FCCAM) y el Centro de Estudios Migratorios Latinoamericanos-. Tras cinco meses de trabajo en los cuales fueron tratados todos los temas sensibles de la ley, la Comisión Asesora elaboró un documento que fue aceptado por el Ministerio del Interior. Este trabajo en conjunto, de la mano de la presión que ejerció un fallo de la Comisión Interamericana de Derechos Humanos que obligaba al país a dictar la reglamentación de la ley de migraciones, dio como resultado la aprobación del Decreto Reglamentario 616/2010 por el Poder Ejecutivo.

Por último, tras el cambio de gobierno y el consiguiente proceso de transición política, las reformas fomentadas desde el año 2015, ha devuelto a la arena política el debate en torno a la ley de migraciones. En virtud de ello, al momento de la publicación de este artículo se han dictado 67 normativas que modifican la ley vigente. Entre ellas, el Decreto de Necesidad y Urgencia 70/2017 ha sido el que ha provocado mayores controversias, al retrotraerse hacia una política de control y selección que permite limitar el ingreso de inmigrantes al país y facilita las expulsiones en sumario. Se trata, entre otras cosas, de una política que dificulta el trámite para obtener la ciudadanía nacional, obstaculiza el derecho de defensa, posibilita la detención y facilita la expulsión. Ello está ligado, en última instancia, al retorno de una retórica que asocia la migración al delito, el narcotráfico y a la inseguridad ciudadana: una narrativa arraigada en la sociedad argentina pese a los esfuerzos de concientización social de las últimas décadas, y profundamente fomentada por los discursos políticos y mediáticos. No obstante ello y pese a haber contado con el aval de la justicia ante los reclamos de organismos de derechos humanos, es innegable reconocer que estamos ante un debate que no ha hecho más que comenzar, y ante el cual las organizaciones de la sociedad civil no permanecerán impávidas.

\section{Organizaciones supranacionales e integración cultural: el MERCOSUR y la UNASUR}

Ahora bien, como fue indicado previamente, ningún proceso de integración migratoria de tal magnitud podría tener éxito sin estar inmersa en una estructura regional que abarcase a todos los países de la región. Tras establecer la voluntad de la libertad de tránsito, la experiencia del MERCOSUR se vio obligada a encarar un proceso de transformación que lo llevó hacia niveles no contemplados en la lógica de un Mercado Común. Entre otras iniciativas, la firma en 1996 del Protocolo de Integración Cultural del MERCOSUR dio
La inclusión cultural en las normativas migratorias de la República Argentina en el contexto sudamericano (1983-2018)

Diego Sebastián Crescentino 
Dossier América Latina: fronteras y zonas fronterizas lugar al MERCOSUR Cultural, que comenzó a operar en 1998 con el objetivo de lograr "la promoción del conocimiento recíproco y el fortalecimiento de las manifestaciones artísticas, los valores, la idiosincrasia de los pueblos, atendiendo a la diversidad cultural de cada uno de ellos". Entre los objetivos de este, se buscó avanzar hacia una mayor cooperación cultural a través de la difusión y divulgación de las expresiones culturales y artísticas del bloque, generando estadísticas culturales de la región para desarrollar políticas públicas eficientes, y llevando adelante políticas, programas y proyectos que tendiesen a ampliar la circulación y comercialización de los bienes culturales dentro de la región (Principios y directrices del Programa MERCOSUR Cultural).

El fortalecimiento de esta función se dio a través del establecimiento de su sede en Argentina en 2006 (CMC/DEC. N $\left.{ }^{\circ} 11 / 06\right)$, la institucionalización de la Secretaría Técnica del MERCOSUR Cultural desde 2010 (Acuerdo de los Ministros de Cultura del MERCOSUR en Río de Janeiro, 20 de noviembre de 2010) y la creación del Fondo MERCOSUR Cultural (CMC/DEC. No. 38/10). En consecuencia, en el año 2012 fueron aprobados su estructura orgánica y su reglamento interno (CMC/DEC. No. 15/12 modificado por CMC/DEC. No. 22/14), designando a la Reunión de Ministros de Cultura como autoridad máxima y estableciendo los órganos dependientes de la misma. Para concluir, en el marco del Comité Coordinador Regional se dio inicio en 2012 a la redacción del "Plan Estratégico de Integración Cultural del MERCOSUR", a fin de establecer objetivos de mediano y largo plazo para respaldar las acciones de integración, cooperación e intercambio cultural del bloque. En este sentido, se establecieron como ejes centrales el desarrollo sostenible, la protección y la promoción de la diversidad cultural, el fortalecimiento de los derechos culturales y la promoción de la economía creativa.

Ello generó como resultado iniciativas como el Patrimonio Cultural del MERCOSUR, el ya mencionado Fondo MERCOSUR Cultural, así como diferentes proyectos llevados a cabo desde entonces. Ahora bien, más allá de la apertura de otras posibilidades que permitiesen lograr una mayor integración, los objetivos del MERCOSUR estuvieron siempre ligados a una integración económica apoyada en los cuatro pilares declarados por el tratado de Asunción ${ }^{7}$. En palabras del secretario de Integración Federal y Cooperación Internacional del Ministerio de Cultura de Argentina, Iván Petrella, a lo largo de la última reunión de Ministros de Cultura del Mercosur Cultural, para esta institución siempre será necesario "defender la cultura en términos económicos no

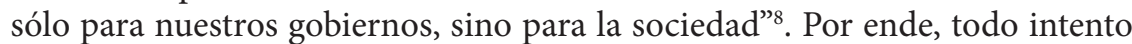

7 Libre circulación de bienes, servicios y factores productivos; establecimiento de un arancel externo común y la adopción de una política comercial común; coordinación de políticas macroeconómicas y sectoriales entre los Estados Partes; compromiso de los Estados Partes de armonizar sus legislaciones en las áreas pertinentes.

8 Web institucional del Mercosur Cultural. Disponible en http://www.mercosurcultural. org/index.php/2015-09-30-12-49-44/146-reunion-de-ministros-de-cultura-pptb-2017 [Consultado el 1/3/2018]. 
de integración cultural estuvo siempre limitado y subordinado a los objetivos económicos del Mercado Común.

Diferente fue el caso de la UNASUR, cuyo Tratado Constitutivo redactado en Brasilia en el año 2008 estableció que su constitución se apoyaba sobre "la historia compartida y solidaria de nuestras naciones, multiétnicas, plurilingües y multiculturales", afirmando "su determinación de construir una identidad y ciudadanía suramericanas y desarrollar un espacio regional integrado". En el mismo sentido, ratificaba entre sus principios rectores el irrestricto respeto a la soberanía, la autodeterminación de los pueblos; la participación ciudadana y pluralismo y el reconocimiento a derechos humanos universales, indivisibles e interdependientes asentados sobre la base de la democracia. Su artículo 2, estableció como objetivo general:

construir, de manera participativa y consensuada, un espacio de integración y unión en lo cultural, social, económico y político entre sus pueblos, otorgando prioridad al diálogo político, las políticas sociales, la educación, la energía, la infraestructura, el financiamiento y el medio ambiente, entre otros, con miras a eliminar la desigualdad socioeconómica, lograr la inclusión social y la participación ciudadana, fortalecer la democracia y reducir las asimetrías en el marco del fortalecimiento de la soberanía e independencia de los Estados.

Asimismo, estableció en sus objetivos específicos la necesidad de lograr una

cooperación en materia de migración, con un enfoque integral, bajo el respeto irrestricto de los derechos humanos y laborales para la regularización migratoria y la armonización de políticas

(artículo 3 inciso $\mathrm{k}$ )

promoción de la diversidad cultural y de las expresiones de la memoria $y$ de los conocimientos y saberes de los pueblos de la región, para el fortalecimiento de sus identidades.

(artículo 3 inciso o)

Para ello fue creado a fines del 2012 en Lima, Perú, el Consejo Suramericano de Cultura como instancia de diálogo y coordinación de políticas para la cooperación en materia cultural. Las prioridades establecidas en su creación fueron promover la diversidad cultural de la región e impulsar la difusión de las distintas expresiones culturales de los pueblos reconociendo la pluralidad de todos los países que conforman el bloque. Otro de los objetivos fue elaborar programas de acción conjunta a favor de la protección de la herencia cultural de los pueblos. En este sentido, en el año 2013 se establecieron las bases de su actuación a través de la aprobación de su Estatuto. Finalmente, por medio de Planes bianuales de Acción se han establecido diversas áreas de acción: interculturalidad, industrias culturales y economía creativa, defensa del patrimonio cultural, comunicación y cultura, artes.
La inclusión cultural en las normativas migratorias de la República Argentina en el contexto sudamericano (1983-2018)

Diego Sebastián Crescentino 
Dossier América Latina: fronteras y zonas fronterizas
Paralelamente resultan interesantes ciertas propuestas derivadas de estos proyectos de integración regional, como la consolidación del Mercado de Industrias Culturales del Sur (MICSUR). Nacida con el fin de "crear y consolidar una plataforma para el conocimiento, difusión, promoción, circulación y comercialización de bienes y servicios generados por las industrias culturales y creativas de la región", esta iniciativa se prepara para su tercera edición, planificada para el mes de noviembre de 2018 en la ciudad brasileña de São Paulo. Propuestas como el Mercosur Cultural, el Consejo Suramericano de Cultura y el MICSUR permiten creer que, aunque incipiente, la construcción de mecanismos supranacionales de integración cultural es posible. Este diálogo deberá llevar, en última instancia, a una integración que permita alterar los imaginarios colectivos en pos del reconocimiento de la pluralidad de las poblaciones. Se trata, como fue mencionado durante la IV Reunión del Consejo Suramericano de Cultura realizada en marzo de 2017 en Ecuador, de profundizar una política cultural desde la región, que fomente una integración que conduzca a la construcción de una identidad común como resistencia a las prácticas hegemónicas.

\section{Conclusiones}

A lo largo del presente trabajo he procurado analizar las políticas públicas migratorias de la República Argentina, identificando específicamente los criterios culturales presentes en las mismas destinados a lograr una integración intercultural eficiente. Para ello, analicé los límites y alcances de las políticas culturales a partir de su definición teórica. Bajo estas nociones, expuse el conjunto de normativas migratorias existentes desde la instauración de la democracia en la República Argentina, llamando la atención sobre el cambio de modelo internacional y regional y su incorporación en el debate de la ley vigente, mencionando posteriormente las iniciativas existentes a nivel regional.

Mencioné de este modo cómo tras la instauración del nuevo orden mundial post-Guerra Fría se dio un doble y contradictorio proceso de integración. En primer lugar, de la mano de las ideas neoliberales comenzó a debatirse la libertad de circulación de bienes y capitales, llevando a graves discordancias a la hora de discutir la libre circulación de personas. En segundo lugar, el auge de las ideas multiculturales profundizó el debate en torno a la tolerancia de la diversidad, estableciendo de la mano nuevos mecanismos de control con "rostro humano" (Domenech 2013: 1). La implementación de estas ideas en la República Argentina se vio contemplada preliminarmente con la reforma constitucional del año 1994, que dio lugar al reconocimiento de ciertos derechos fundamentales a través de la inclusión de los tratados internacionales en la cima de la pirámide normativa. Sin embargo, fue recién a través de la Ley de Migraciones promulgada en el año 2004 que estos derechos se vieron plasmados en la legislación migratoria. 
Aun así, es importante resaltar que lo novedoso de la ley de migraciones vigente fue la adopción de caracteres multiculturales. En este sentido, si bien la estructura demográfica argentina ha sido multicultural y multiétnica durante toda su historia, fue la primera normativa migratoria de la historia argentina en reconocer una realidad multicultural, lo cual en su momento representó un verdadero desafío. Sin embargo, "no [sólo] se trata[ba] de amontonar grupos uno al lado del otro al modo de los Estados Unidos, fingiendo una multiculturalidad que sólo oculta la hegemonía de uno de los participantes" (Vior 2007: 10). El verdadero desafío era reconocer efectivamente esa realidad multicultural y multiétnica, asumiendo las responsabilidades derivadas de esta decisión a través del fomento de políticas migratorias y culturales inclusivas.

Estos avances observados en términos legales han llevado a reconocer que la idea de la preservación y protección de una identidad nacional ha cambiado. Es hora de poner fin a la reproducción de esta lógica decimonónica asimilacionista que hoy se esconde detrás de la máscara liberal de la tolerancia y el respeto. Por ello, si bien la actualización de los principios sobre los cuales se asienta el accionar del Estado a partir de la promulgación de la Ley 25.871 sí refleja el cambio del modelo multicultural imperante a lo largo de las últimas tres décadas, la eficiencia de la normativa vigente en Argentina no va más allá del reconocimiento de principios legales y políticas locales puntuales. Es por ello que para la futura formulación de políticas culturales se hace necesario partir de un diagnóstico que reconozca la presencia de las múltiples identidades que se encuentran en el territorio de la República Argentina.

Sin negar los aportes y avances realizados por esta normativa migratoria, es fundamental partir de la comprensión de la coyuntura histórica y de las distintas lógicas en juego para continuar con la reforma de la misma en pos de lograr una verdadera inclusión cultural. En este sentido, el ámbito de la integración intercultural (parcialmente comprendido por la ley) ha sufrido grandes carencias a la hora de hacer un diagnóstico y perseguir la aplicación de políticas de esta índole.

Frente a ello, si bien actualmente se percibe un retorno hacia políticas migratorias represivas asociadas a narrativas de exclusión, el retorno a un mundo de fronteras cerradas, identidades nacionales inmutables y políticas de exclusión es inimaginable. Es fundamental formular un diagnóstico a largo plazo que persiga un cambio en la cosmovisión del Estado. De este modo, uno de los mayores desafíos que los Estados de la región tendrán por delante, si pretenden superar estas carencias, es continuar avanzando hacia la integración de políticas conjuntas que permitan lograr un accionar que trascienda los límites estatales con las herramientas que ya han sido creadas.

A partir de los análisis que sean realizados de ahora en adelante, es necesario observar con atención las alternativas superadoras que proponen los distintos actores interventores en la vida social, cultural, política y económica a nivel local, nacional y regional. Es sólo a través de la elaboración de políticas que superen la lógica asimilacionista que será posible buscar nuevas soluciones
La inclusión cultural en las normativas migratorias de la República Argentina en el contexto sudamericano (1983-2018)

Diego Sebastián Crescentino 
Dossier América Latina: fronteras y zonas fronterizas que respeten las regiones, que coordinen los esfuerzos y que aprovechen las redes organizativas de una sociedad participante para lograr la adopción de un sistema alterno, creativo e inclusivo que verdaderamente contemple a la migración como un derecho humano.

\section{Referencias bibliográficas}

Acuerdo sobre residencia para nacionales de los Estados Partes del MERCOSUR (2002), publicado el 06.12.2002, Brasilia.

Acuerdo de los Ministros de Cultura del MERCOSUR (2010), publicado el 20.11.2010, Río de Janeiro.

Bobbio N. (1991), El tiempo de los derechos, Sistema, Madrid.

Ceriani Cernadas P., Morales D. (2011), Argentina. Avances y asignaturas pendientes en la consolidación de una politica migratoria basada en los Derechos Humanos, no 559e, Centro de Estudios Legales y Sociales, Federación Internacional de Derechos Humanos, Buenos Aires.

Convención de las Naciones Unidas sobre los Derechos de los Migrantes (2003).

Convención Internacional sobre la Protección de los Derechos de Todos los Trabajadores Migratorios y de sus Familiares (2003).

Correa V. (2006), El papel de la sociedad civil en los derechos humanos de los migrantes, CELADE, Santiago de Chile.

Constitución de la Nación Argentina (2013), Gráfica Campichuelo, Buenos Aires.

Declaración de Integración Cultural del MERCOSUR (2008), publicada el 12/06/2008.

Decreto-Ley General de Migraciones y Fomento de la Inmigración 22.439 (1981), publicada en el Boletín Oficial el 27.03.1981, Buenos Aires.

Decreto 1.023 (1994), publicado en el Boletín Oficial el 05.07.1994, Buenos Aires.

Decreto 1.117 (1998), publicado en el Boletín Oficial el 06.10.1998, Buenos Aires.

Decreto 616 (2010), publicado en el Boletín Oficial el 06.05.2010, Buenos Aires.

Decreto de Necesidad y Urgencia 70 (2017), publicado en el Boletín Oficial el 30.01.2017, Buenos Aires.

Disposición 37.130 (2008), Dirección Nacional de Migraciones, publicada en el Boletín Oficial el 26.05.2008, Buenos Aires.

Domenech E. (2005), Inmigración, Estado y educación en Argentina ¿Hacia nuevas políticas de integración? XXV Conferencia Internacional de Población de la IUSS realizada en Tours, Francia, http://webiigg.sociales.uba.ar/pobmigra/archivos/domenech.pdf consultado en: 01.03.2018.

Domenech E., Magliano M. J. (2008), Migración e inmigrantes en la Argentina reciente: Políticas y discursos de exclusión/inclusión, Siglo del Hombre, CLACSO, Bogotá.

Domenech E. (2010), La "nouvelle politique migratoire" en Argentine: les paradoxes du programme "Patria Grande", "Problèmes d’Amérique latine", vol. 1, no 75, pp. 37-60.

Domenech E., (2013), "Las migraciones son como el agua”: Hacia la instauración de políticas de "control con rostro humano", "Revista Latinoamericana Polis", no 35, On-line. 
Estatuto del Consejo Suramericano de Cultura (CSC) (2013).

Estructura orgánica y reglamento interno del MERCOSUR Cultural (2012), MERCOSUR/ CMC/DEC. no 15/12.

Estructura orgánica y reglamento interno del MERCOSUR Cultural (2014), MERCOSUR/ CMC/DEC. no 22/14.

Fondo MERCOSUR Cultural (2010), MERCOSUR/CMC/DEC. no 38/10.

García Canclini, N. (2001), La globalización imaginada, Paidós, Buenos Aires.

Gavazzo N. (2004), Identidad boliviana en Buenos Aires: Las políticas de integración cultural, "THEOMAI", no 9, On-line.

Grimson A. (2006), Nuevas xenofobias, nuevas políticas étnicas en la Argentina, en: Migraciones regionales hacia la Argentina. Diferencia, desigualdad y derechos, A. Grimson y E. Jelin (comps.), Prometeo, Buenos Aires, pp. 69-99.

Giustiniani R. (comp.) (2004), Migración: Un derecho humano. Prometeo Libros, Buenos Aires.

Ley 817 de Inmigración y Colonización (1876), publicada en el R. N. 1874/77, Buenos Aires.

Ley 4.144 de Residencia de Extranjeros (1902), publicada en el Boletín Oficial el 26.11.1902, Buenos Aires.

Ley 7.209 de Defensa Social (1910), Publicada en el Boletín Oficial el 26.10.1910, Buenos Aires.

Ley 24.309 (1993), publicada en el Boletín Oficial el 31.12.1993, Buenos Aires.

Ley 24.515 (1995), publicada en el Boletín Oficial el 03.08.1995, Buenos Aires.

Ley de Migraciones 25.871 (2003), publicada en el Boletín Oficial el 21.01.2004, Buenos Aires.

Mármora L. (2004), Las leyes de migraciones como contexto normativo (De la "Ley Videla" a la "Ley de Migraciones 25.871"), en: Migración: Un derecho humano, R. Giustiniani (comp.), Prometeo Libros, Buenos Aires, pp. 59-65.

Mardones P. (2005), La incorporación de los migrantes a la agenda de los Derechos Humanos en la Argentina, Centro de Estudios Legales y Sociales, Buenos Aires, http://www. alpacaproducciones.com.ar/la\%20incorporacion.pdf consultado en: 01.03.2018.

Mercosur Cultural (2017), Reunión de Ministros de Cultura - PPTB 2017, http://www. mercosurcultural.org/index.php/2015-09-30-12-49-44/146-reunion-de-ministros-decultura-pptb-2017 consultado en: 15.07.2018.

Modolo V., Novick S., Mera G. (2010), Migraciones y MERCOSUR: una relación inconclusa, Catálogos, Buenos Aires.

Novick S. (2004), Una nueva ley para un nuevo modelo de desarrollo en un contexto de crisis y consenso, en: Migración: Un derecho humano, R. Giustiniani (comp.), Prometeo Libros, Buenos Aires, pp. 66-86.

Oteiza E. (2004), Hacia una nueva política migratoria argentina. Inmigración, integración $y$ derechos humanos, en: Migración: Un derecho humano, R. Giustiniani (comp.), Prometeo Libros, Buenos Aires, pp. 87-111.

Pacecca M. I. (1997), Políticas migratorias y administración pública: la Dirección Nacional
La inclusión cultural en las normativas migratorias de la República Argentina en el contexto sudamericano (1983-2018)

Diego Sebastián Crescentino 
Dossier América Latina: fronteras y zonas fronterizas de Migraciones, 1876-1996, V Congreso Argentino de Antropología Social, Universidad Nacional de la Plata, La Plata, http://www.equiponaya.com.ar/congresos/contenido/ laplata/LP4/46.htm consultado en: 02.03.2018.

Pacecca M. I., Courtis C. (2008), Inmigración contemporánea en Argentina: dinámicas $y$ políticas, Naciones Unidas, Santiago de Chile.

Plan Sudamericano de Desarrollo Humano de las Migraciones (2010), publicado el 26/10/2010, Cochabamba.

Protocolo de Integración Cultural del MERCOSUR (1996), MERCOSUR/CMC/DEC., no. $11 / 96$.

Resolución 2/2013 de la UNASUR (2013).

IV Reunión del Consejo Suramericano de Cultura (2017), realizado en marzo de 2017, Quito.

VI Reunión Ordinaria del Consejo de Jefas y Jefes de Estado y de Gobierno de UNASUR (2012), realizada el 30.11.2012, Lima.

Sede permanente del MERCOSUR Cultural (2006), MERCOSUR/CMC/DEC., no 11/06.

Tratado Constitutivo de la Unión de Naciones Suramericanas (2008), Brasilia.

Vior E. (2007), Tareas pendientes del Estado argentino para ajustarse a la nueva política de inmigración, Foro de la UNESCO para el Diálogo entre las Ciencias Sociales y la Política, realizado en la Universidad Nacional de Córdoba, http://www.ddhhmigraciones.com.ar consultado en: 02.03.2018.

Yúdice G. (2002), El recurso de la cultura: usos de la cultura en la era global, Gedisa, Barcelona.

Žižek S. (1998), Multiculturalismo o la lógica cultural del capitalismo multinacional, Editorial Paidós, Buenos Aires. 